\title{
Formulation and evaluation of wound healing dermal patch
}

\author{
Nilani P.*, Pranavi A., Duraisamy B., Damodaran P., Subhashini V. and Elango K. \\ Department of Pharmacognosy, JSS College of Pharmacy, Off Campus of JSS University, Rocklands, \\ Ootacamund, 643001 Tamilnadu, India.
}

Accepted 8 August, 2011

\begin{abstract}
In this study, the wound healing activity of total aqueous extract and the mucilage of leaves of plant Cocculus hirsutus (L) Diels was evaluated on excision wound model. Dermal films were prepared using total aqueous extract, mucilage and polyvinyl alcohol as a polymer base. The prepared polysaccharide solutions of the total extract and the isolated mucilage were evaluated for its physiochemical properties and total bacterial count. The prepared dermal patches were subjected biodegradation studies. The results indicate statistically significant wound healing response of the dermal patch containing the aqueous extract and the mucilage of leaves of plant $C$. hirsutus when compared with control group and groups subjected to standard marketed medicated dermal patch. The cost effective factor and biodegradation of the prepared dermal wound healing patch was also found to be significant.
\end{abstract}

Key words: Cocculus hirsutus (L.) Diels, wound healing, excision wound model, Dermal patches.

\section{INTRODUCTION}

Wound is a breach formed in the normal continuvum of the cellular and molecular structure of the body thereby creating a disruption in the cellular, anatomic and as well as in their functional continuity. Wound healing or wound repair is an intricate process in which the skin or organ or tissue repairs itself after injury. It comprises of a continuous sequence of inflammation and repair in which epithelial endothelial inflammatory cells, platelets and fibroblasts briefly come together outside their normal domains, interact to restore a semblance of their usual discipline and having done to resume their normal function (Clark, 1993; Singer and Clark, 1999; Sahl and Clever, 1994). In medicine today, the best-known and widely used approach for delivering drugs and medications through the skin without using needles is dermal patch technology. The patch used for the wound healing also includes an ultra-concentrated formula infused into a small discreet dermal patch which sticks to the body. This uses advanced physiological technology to introduce the formula into the user's bloodstream in a

\footnotetext{
*Corresponding author. E-mail: p.nilani@jsscpooty.org.
}

controlled, timely manner further showing the wound healing phases. The dermal patch technology has proven to be fastest, easiest, safest and most economical way to help wound to heal (Leong, 1991). Nowadays, more attention is paid to pollution caused by non biodegradable synthetic polymers which has resulted in worldwide concern on biodegradable substances such as polysaccharide, lipid, protein and other composite films (Karlsson and Albertsson, 1998).

Biodegradation is a natural process by which organic chemicals in the environment are converted to simpler compounds. Biodegradation can only occur within the biosphere as microorganisms play a central role in the biodegradation process. Polyvinyl alcohol (PVA) is the most readily biodegradable of vinyl polymers (Wade and Weller, 2002). Thus with a new dimension for the use of polymeric materials in or as drug delivery devices involves incorporation of biodegradability into the drug delivery system. However, a number of degradable polymers are potentially useful for this purpose including a variety of synthetic and natural substances. The use of intentionally degradable polymers in medicine has been brought into prominence with new innovations in drug delivery systems through this study. 


\section{MATERIALS AND METHODS}

\section{Plant material}

Leaves of Cocculus hirsutus collected from Tirupathi of Andhra Pradesh of India were authentified by Dr. K. Madhava Chetty, herbarium keeper, Department of Botany, Sri Venkateshwara University, Tirupathi, Andhra Pradesh.

\section{Preparation}

\section{Total aqueous extract}

The leaves were collected and shade dried. The powdered leaves were defatted using petroleum ether. The defatted material $(50 \mathrm{~g})$ was soaked in distilled water $(500 \mathrm{ml})$ at room temperature for $12 \mathrm{~h}$. The resulting mass was strained through muslin cloth. The residue was collected and subjected for freeze drying.

\section{Extraction of mucilage}

The leaves were collected and shade dried. The powdered leaves were defatted using petroleum ether. The defatted material $(50 \mathrm{~g})$ was soaked in distilled water $(500 \mathrm{ml})$ at room temperature for half an hour. The resulting mass was strained through muslin cloth and subjected to freeze drying.

\section{Mixing of material/solution preparation}

Polysaccharide based dermal patch solution -I was prepared by dissolving the polyvinyl alcohol in the aqueous extract of $C$. hirsutus (L.) in the ratio of 1:6.6. The aforementioned solution was being subjected to sonication at $45^{\circ} \mathrm{C}$ until it was completely dissolved. Polysaccharide based dermal patch solution-II was prepared by dissolving the 'polyvinyl' alcohol in the mucilage of $C$. hirsutus (L.) in the ratio of $1: 6.6$. The aforementioned solution was subjected to sonication at $45^{\circ} \mathrm{C}$ until it is completely dissolved.

\section{Film preparation/film casting}

The dermal patch was prepared by casting on the mould plate method. $15 \mathrm{ml}$ of the polymer solution I and II were poured into the two mould of size $10 \times 10 \mathrm{~cm}$. The solvent was allowed to evaporate at room temperature and after drying the patch was removed from the mould.

\section{Physicochemical evaluation of the polymer solution}

The prepared polysaccharide solutions of the total extract and the isolated mucilage were evaluated for its $\mathrm{pH}$, viscosity, bloom strength and total bacterial count (Hindustan et al., 2010).

\section{pH}

The $\mathrm{pH}$ of the polysaccharide based dermal patch solution was determined by Systronics- $\mathrm{P}^{\mathrm{H}}$ meter $\mu$ pH system 361 .

\section{Viscosity}

Viscosity of polysaccharide based dermal patch solution was evaluated by pipette viscometer (Lab India).

\section{Bloom strength}

The bloom strength of the solution was determined by Stevens LFRA Texture Analyzer (Sherfortshire, UK).

\section{Total bacterial count}

The total bacterial count of the polysaccharide based dermal patch solution was determined using 'standard plate count method'.

\section{Physicochemical evaluation of the biopolymer dermal patch}

The prepared films were evaluated for its uniformity of weight, thickness measurement, melting point, moisture content and biodegradation (Hindustan et al., 2010).

\section{Uniformity of weight}

This was done by weighing three different patches of the individual batch. Taking the uniform size at random and average weight will be calculated.

\section{Thickness measurement}

Patch thickness was measured with Mitutoyo digimatic caliper (IDC112, Mitutoyo Corp, Kawasaki, Kanagawa, Japan) at five random positions of each film.

\section{Melting point}

The melting point of the polysaccharide based dermal patch was determined in open capillaries by using Veego VMP-1 apparatus.

\section{Moisture content}

The moisture content of the patch was determined using Sartorious electronic moisture balance.

\section{Biodegradation}

The polysaccharide based dermal patches were cut into similar pieces $(1 \times 1 \mathrm{~cm})$. The films were weighed separately and observed under system microscope-Motic image plus and scanning electron micrography. Then the patches will be packed in a small cloth bags made up of muslin cloth and again weighed. The bags were buried in the soil collected from different regions. After every 5 days, the weights and the microscopic images were taken up to 25 days. The weight differences and the structural differences in the microscopic images were observed. The soil was tested for its parameters in horticulture, Soil Testing Laboratory, Ooty.

\section{Cost effective factor}

The cost effective factor was analyzed by comparing the prepared wound healing dermal patch with that of marketed synthetic wound healing patches or plasters with the method paired t-test by using the software called Graphpad.prism.5.downasrchive.

\section{Wound healing activity}

Adult wistar albino rats of either sex weighing (180 to $220 \mathrm{~g}$ ) were 
Table 1. Physicochemical evaluation of the polymer solution.

\begin{tabular}{lcc}
\hline Physicochemical parameter & Polysaccharide biopolymer solution-I & Polysaccharide biopolymer solution-II \\
\hline Viscosity (mps) & 754.29 & 785.16 \\
Bloom strength $(\mathrm{g})$ & 60 & 72 \\
$\mathrm{P}^{\mathrm{H}}$ & 3.80 & 3.50 \\
Total bacterial count (per g) & Absent & Absent \\
\hline
\end{tabular}

Table 2. Physicochemical evaluation of the dermal patch.

\begin{tabular}{lcccc}
\hline Sample & Uniformity of weight $(\mathbf{1} \times \mathbf{1})(\mathbf{m g})$ & Thickness $(\mathbf{m m})$ & Melting point $\left({ }^{\circ} \mathbf{C}\right)$ & Moisture content $(\%)$ \\
\hline Sample patch I & 4.31 & 0.02 & 58 & 18.68 \\
Sample patch II & 4.25 & 0.02 & 57 & 16.81 \\
\hline
\end{tabular}

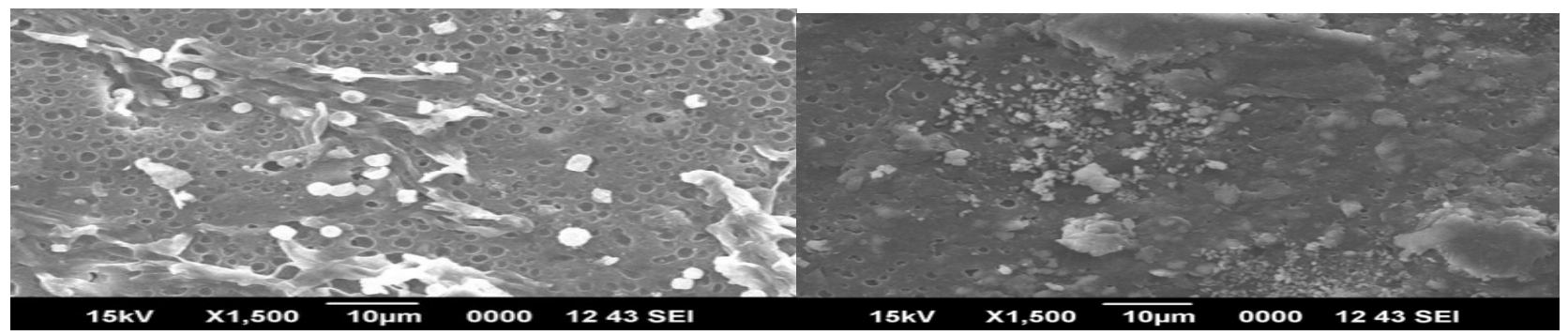

(a)

(b)

Figure 1. Scanning electron micrograph of polysaccharide based dermal patch, (a) before biodegradation; (b) after biodegradation in red soil.

grouped, containing six animals in each group. The animals were anaesthetized and were deplicated on the back. One excision wound was inflicted by cutting away about a $50 \mathrm{~mm}^{2}$ of skin from a predetermined area; the wound was left undressed to the open environment. Then the test, standard and control patches were applied on the wound and the progressive change in wound area were monitored planimetrically by tracing the wound margin or graph paper every alternative day. The model was used to measure contraction and wound closure time.

\section{RESULTS}

The present study was focused on the selection and collection of the plant material. Total aqueous extract was prepared by maceration process and mucilage rich in polysaccharide was also isolated from the leaves of $C$. hirsutus. The qualitative chemical analysis of total aqueous extract and the mucilage and the aqueous extract showed the presence of carbohydrates, glycosides, alkaloids, saponins, flavanoid etc. Clear and viscous sample solutions (I and II) were prepared and were applied on a glass plate $\left(9 \times 15^{2}\right)$. The solution I comprises of aqueous extract and solution II comprises of mucilage. The polymer solution was prepared in the ratio of 1:6.6 (drug:PVA). The film was casted by pouring the solution onto the plates and followed by smearing. The prepared films were peeled from the plates and the films showed good film forming property (filmogenicity). The prepared biopolymer solutions and the formulated film were evaluated for their physicochemical properties in the fifth stage. The $\mathrm{pH}$, bloom strength, viscosity and total bacterial count of the polymer solution is tabulated in Table 1. The formulated biopolymer dermal film I and film II were tested for uniformity of weight, thickness, melting point and moisture content. The average weight of the patches $(1 \times 1)$ were found to be 4.31 and $4.25 \mathrm{mg}$ with the thickness of $0.2 \mathrm{~mm}$. Moisture content of the film was found to be ranging from 18.68 to $16.81 \%$ and the results are shown in the Table 2. The biodegradation studies for the polysaccharide based dermal film (Sample I) was performed. The study was carried out in black loamy soil, red and sandy soil for 25 days. The physical changes in polysaccharide based dermal film before and after biodegradation were observed using scanning electron microscopy and the results of the study are illustrated in Figures 1, 2 and 3 . The weight variation of the bio polymer is represented in Graphs 1 to 3 and Figure 1. Cost effective factor was studied and the cost of developed polysaccharide based dermal film was compared with that of marketed medicated plaster. 


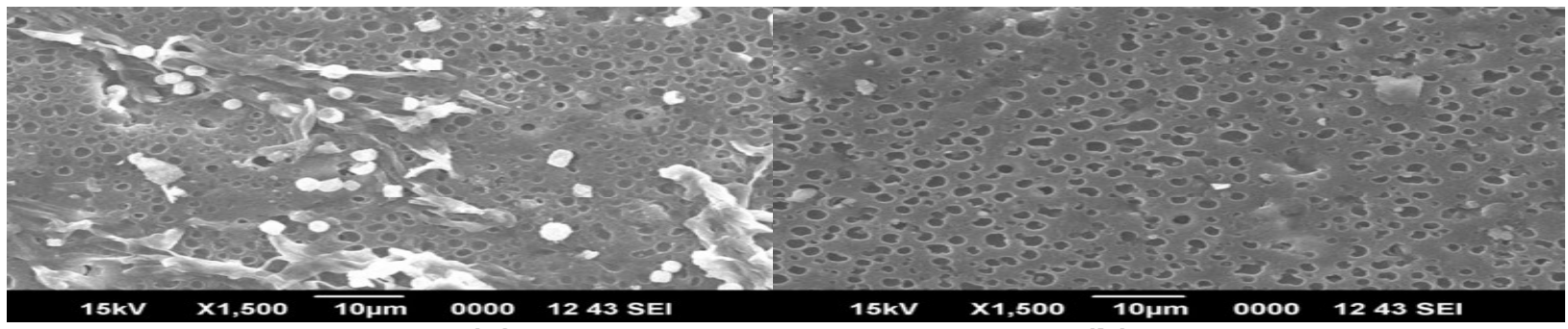

(a)

(b)

Figure 2. Scanning electron micrograph of polysaccharide based dermal patch, (a) before biodegradation; (B) after biodegradation in sandy soil.

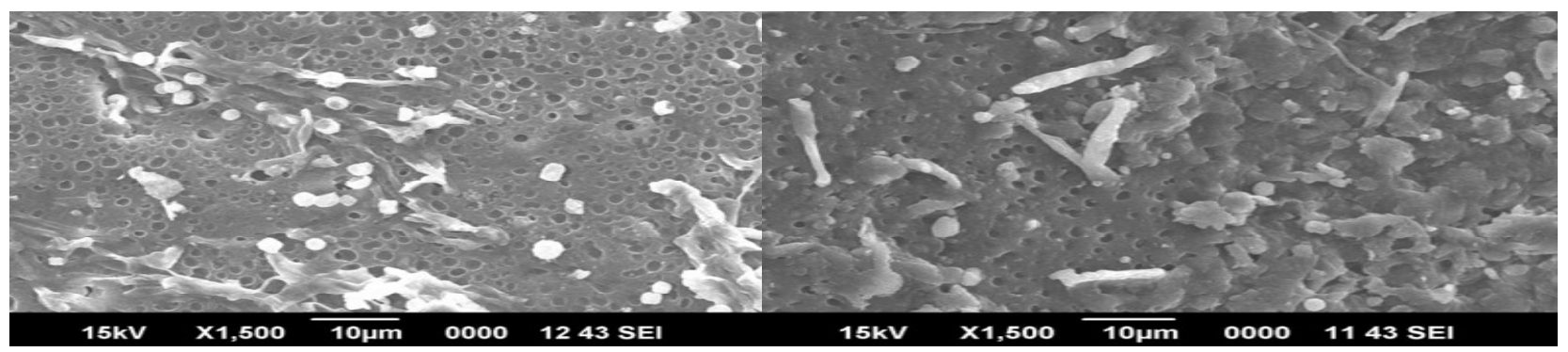

(a)

(b)

Figure 3. Scanning electron micrograph of polysaccharide based dermal patch (A) before biodegradation (B) after biodegradation in black loamy soil.

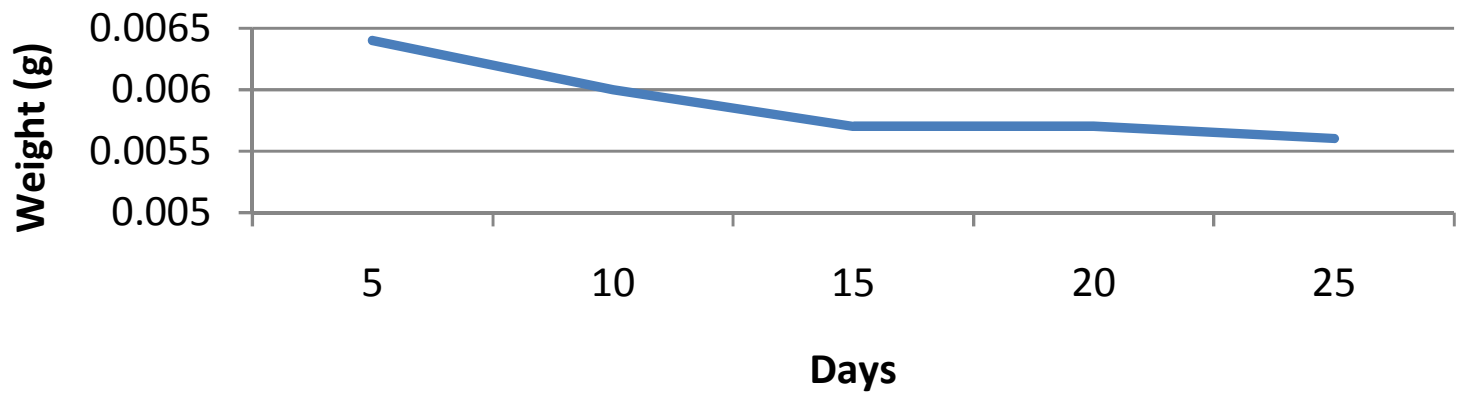

Graph 1. Biodegradation in red soil.

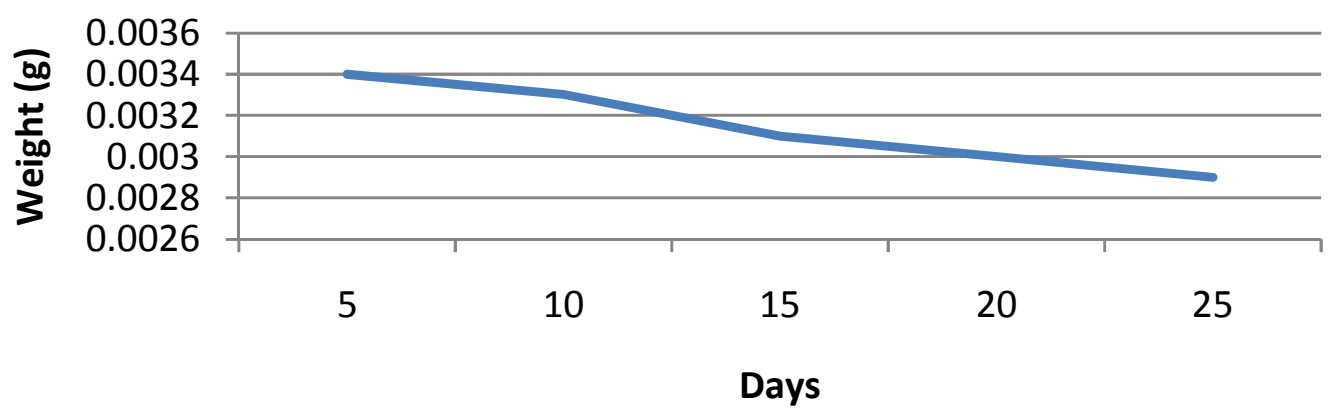

Graph 2. Biodegradation in sandy soil. 


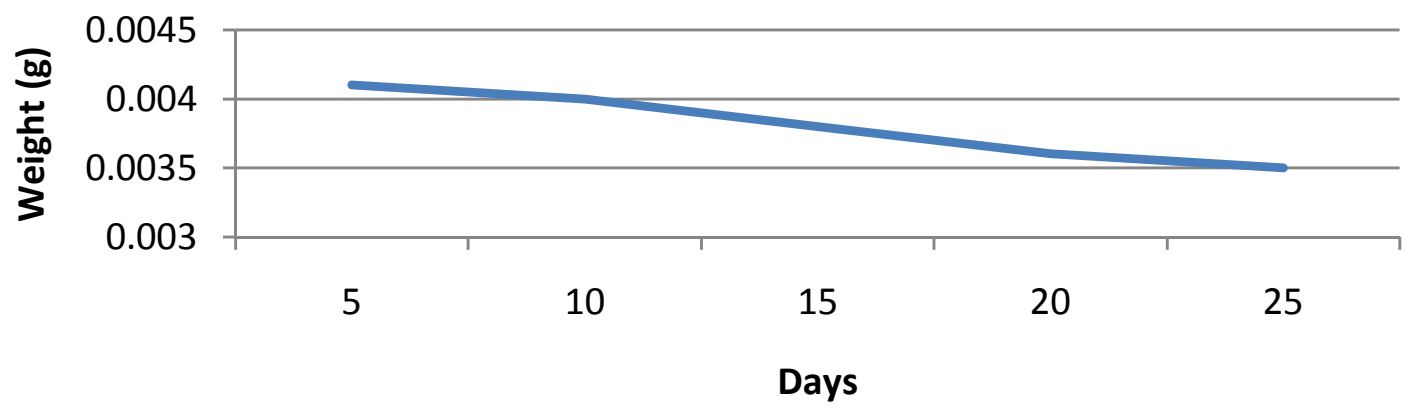

Graph 3. Biodegradation in black loamy soil.

Table 3. Wound healing activity of the dermal patch.

\begin{tabular}{lccccccc}
\hline Treatment & 0 day & 1st day & 4th day & 8th day & 12th day & 16th day & 21st day \\
\hline Control & $47.17 \pm 1.83$ & $47.00 \pm 1.82$ & $38.50 \pm 2.84$ & $11.83 \pm 1.7^{*}$ & $2.0 \pm 0.0^{*}$ & $0.16 \pm 0.16^{*}$ & $0.0 \pm 0.0$ \\
$\begin{array}{l}\text { Sample 1: Dermal patch with } \\
\text { total aqueous extract }\end{array}$ & $42.67 \pm 2.15$ & $42.50 \pm 2.21$ & $40.00 \pm 2.02$ & $11.83 \pm 1.13^{*}$ & $2.0 \pm 0.0^{*}$ & $0.0 \pm 0.0$ & $0.0 \pm 0.0$ \\
$\begin{array}{l}\text { Sample 2: Dermal patch with } \\
\text { mucilage }\end{array}$ & $43.17 \pm 2.30$ & $42.83 \pm 2.27$ & $40.33 \pm 2.07$ & $19.19 \pm 1.01^{*}$ & $6.16 \pm 0.7^{*}$ & $1.66 \pm 0.42^{*}$ & $0.0 \pm 0.0$ \\
Standard: Medicated plaster & $44.00 \pm 3.77$ & $43.67 \pm 3.45$ & $40.00 \pm 3.55$ & $2.167 \pm 0.16$ & $0.0 \pm 0.0$ & $0.0 \pm 0.0$ & $0.0 \pm 0.0$ \\
\hline
\end{tabular}

Data expressed as mean \pm SEM, one way ANOVA followed by Dunnett's multiple comparison test, ${ }^{*} \mathrm{P}<0.05$; values are expressed in mm ${ }^{2}$.

The results of the study reveals that the developed polysaccharide based biopolymer dermal film is cost effective when compared to marketed medicated patch. The wound healing activity of the prepared polysaccharide based dermal film was carried out according to OECD guidelines using excision wound model. The developed polysaccharide based dermal film I and II containing total extract (40\%) and mucilage (40\%) of $C$. hirsutus individually was subjected for wound healing study and revealed significant wound healing activity within 12 to 16 days when compared with the marketed medicated plaster. The results are illustrated in Table 3.

\section{Conclusion}

A polysaccharide based biopolymer dermal film was developed in the present study to support wound healing activity utilizing total aqueous extract and mucilage from the leaves of $C$. hirsutus. The wound healing property of the aqueous extract was significant when compared to the mucilage of the leaves of $C$. hirsutus. The selection of the plant $C$. hirsutus for the present wound healing activity was based on the ethnobotanical information obtained from the tribal people living in and around Tirumala Hills, Andhrapradesh since the plant is widely used by the native and tribal people for treating ulcer. Synthetic polymers are gradually being replaced by biodegradable materials especially those derived from replenishable natural resources. The society's current views on environmental responsibility make this an ideal time for biodegradable polymer development which helps the future growth of biopolymers. Synthetic dermal patches, plasters, surgical/wound dressings that are available in market are found to be non-biodegradable and considerably pollute the environment. An effort was made through this study to prepare a complete biodegradable dermal patches using natural polymer to support wound dressing and healing. In the present, dermal films were prepared using aqueous extract and mucilage from the leaves of $C$. hirsutus and by cross linking with polyvinyl alcohol in the ratio 1:6.6. Complete biodegradation of the dermal film was observed within 25 days in sandy soil followed by black loamy and red soil. The dermal film was nontoxic with good filmogenicity and revealed significant wound healing activity on excision wounds in animal model within 12 to 16 days. To conclude the polysaccharide based biopolymer, dermal film may prove as a suitable alternative or a substitute for conventional medicated plasters or patches. Thus with a new dimension for the use of bio polymeric materials as drug delivery devices involves incorporation of biodegradability into the drug delivery system.

Through this study the use of plant based biodegradable polymers in medicine has been brought into prominence as a new innovation in drug delivery systems. The developed polysaccharide based biopolymer 
dermal film possesses the following advantages:

i) Ecofriendly - completely biodegradable.

ii) Economical - cost effective.

iii) Effective - potent wound healing activity in minimum duration.

iv) Innovative - new innovation in drug delivery systems as a polysaccharide based biopolymer wound healing dermal patch.

\section{REFERENCES}

Clark R (1993). Basics of cutaneous wound repair. J. Dermatol. Surg. Oncol., 19: 693-706.

Hindustan AA, Pilli Y, Ravindra B, Gangadhar SCG, Rama K, Chandana R, Chitta SK (2010). Fabrication and in-vitro evaluation of Diltiazem Hydrochloride-Ficus glomerata Fruit Mucilage Transdermal Patches; JITPS, 1(2): 86 - 97.

Karlsson RR, Albertsson AC (1998). Biodegradable polymers and environmental interaction. Polymer Eng. Sci., 38(8): 1251-1253.

Leong KW (1991). Biodegradable polymers as drug delivery systems. In: Tarcha PJ, editors, Polymers for controlled drug delievery. CRC Press: Boca Raton; p. 128.
Sahl W, Clever H (1994). Cutaneous scars: Part I. Int. J. Dermatol., 33: 681-91.

Singer A, Clark R (1999). Cutaneous wound healing. N. Engl. J. Med., 341: 738-746.

Wade A, Weller PJ (2002). Poly Vinyl Alcohol; Hand Book of pharmaceutical excipients; 2: 135-145. 